University of Nebraska - Lincoln

DigitalCommons@University of Nebraska - Lincoln

USDA National Wildlife Research Center - Staff Publications
U.S. Department of Agriculture: Animal and Plant Health Inspection Service

2010

\title{
The effect of enclosure type on the behavior and heart rate of captive coyotes
}

Stacey P. Brummer

USDA-APHIS-Wildlife Services

Eric M. Gese

USDA/APHIS/WS National Wildlife Research Center, eric.gese@usu.edu

John A. Shivik

USDA-APHIS-Wildlife Services

Follow this and additional works at: https://digitalcommons.unl.edu/icwdm_usdanwrc

Part of the Environmental Sciences Commons

Brummer, Stacey P.; Gese, Eric M.; and Shivik, John A., "The effect of enclosure type on the behavior and heart rate of captive coyotes" (2010). USDA National Wildlife Research Center - Staff Publications. 893. https://digitalcommons.unl.edu/icwdm_usdanwrc/893

This Article is brought to you for free and open access by the U.S. Department of Agriculture: Animal and Plant Health Inspection Service at DigitalCommons@University of Nebraska - Lincoln. It has been accepted for inclusion in USDA National Wildlife Research Center - Staff Publications by an authorized administrator of DigitalCommons@University of Nebraska - Lincoln. 


\title{
The effect of enclosure type on the behavior and heart rate of captive coyotes
}

\author{
Stacey P. Brummer*, Eric M. Gese, John A. Shivik \\ USDA Wildlife Services National Wildlife Research Center, Logan, UT 84322, USA
}

\section{A R T I C L E I N F O}

\section{Article history:}

Accepted 28 April 2010

Available online 3 June 2010

\section{Keywords:}

Coyote

Canis latrans

Enclosure

Behavior

Heart rate

Stress

\begin{abstract}
A B S T R A C T
The potential for captivity to elicit changes in animal behavior and physiology is well known. Recent research on captive populations has examined the effect of feeding protocols, enclosure types, and enrichment programs on indices of stress and displays of species-typical behaviors. We investigated the impact of enclosure type upon captive coyotes (Canis latrans) by examining differences in coyote behavior and heart rate, among $3.3 \mathrm{~m}^{2}$ kennels $(\mathrm{K}), 65.5 \mathrm{~m}^{2}$ small pens $(\mathrm{S})$, and $1000 \mathrm{~m}^{2}$ large pens $(\mathrm{L})$. Time budgets and repertoire of species-specific behaviors were compared among each enclosure type and to a sample of wild (W) coyotes. Baseline heart rates and heart rate (HR) responses to food delivery and fecal collection (measured as mean heart rate and latency of heart rate to return to baseline) were also compared among treatments. We found that behavioral budgeting, but not repertoire, differed significantly among enclosure types. Relative to small and large pen enclosures, coyotes maintained in kennels exhibited the greatest amount of stereotypic behavior $(P<0.0001)$. Coyotes kept in large pens were most similar to wild coyotes in the percentage of time they spent performing exploratory (K: $2.7 \%$; S: $4.9 \%$; L: 8.5\%; W: $12.0 \%$ ) and stand and scan (K: 8.0\%; S: 16.4\%; L: 22.0\%; W: 22.3\%) behaviors. Heart rate analysis showed that baseline heart rates and heart rate responses to food delivery did not differ significantly among enclosure types. Mean heart rate responses to fecal collection were significantly higher for kennel coyotes than for those maintained in large pens $(P=0.04)$. Similarly, latency to return to baseline was significantly higher in kennels than in small and large pens $(P=0.001)$. These results suggest that enclosure type does influence coyote behavior and heart rate responses to some human activities.
\end{abstract}

Published by Elsevier B.V.

\section{Introduction}

Concerns about animal welfare, the potential for environmental conditions to influence farm productivity, research observations, and conservation efforts in zoos have prompted numerous studies on the effects of captivity on animal behavior and physiology (Carlstead et al., 1993;

\footnotetext{
* Corresponding author at: USDA/APHIS/WS/NWRC, Utah State University, Predator Project, BNR 163, Logan, UT 84322-5295, USA.

Tel.: +1 435245 6091x3116; fax: +1 4352453156 .

E-mail address: Stacey.P.Brummer@aphis.usda.gov (S.P. Brummer).
}

Meijer et al., 2006). The impact of the captive environment upon an individual may be influenced by several factors including species, age, reproductive status, and previous experience; however, detrimental changes to behavior and physiology become increasingly prevalent as the housing environment becomes more barren and spatially or socially restrictive (Hubrecht, 2002; Meehan and Mench, 2007). Adverse changes such as displays of self-injurious behaviors, increased restlessness and vigilance, and reduced fecundity have been linked with stress and inadequate housing conditions (Fraser and Broom, 1997; Morgan and Tromborg, 2007). Chronic stress in the captive environment can be caused by repeated exposure to inescapable 
stressors such as an inability to avoid unwanted interactions with caretakers, unpredictable husbandry schedules, and handling for experimental procedures (Carlstead et al., 1993; Meijer et al., 2006). Restrictive enclosures exacerbate the impact of these stressors by prohibiting species appropriate responses, reducing flight distance or both (Morgan and Tromborg, 2007). Thus, enclosure type has been the focus of much research regarding captive animal welfare.

Several attributes of captive animal housing have been investigated using behavioral indices of stress (Brown and Grunberg, 1996; Jarvis et al., 2002). Abnormal behaviors such as stereotypies, excessive grooming, increased vocalizations, increased activity, paw lifting, and increased levels of fearfulness and reactivity to unpredictable events are associated with canids experiencing chronic stress, inadequate sensory stimulation or both (Hetts et al., 1992; Nimon and Broom, 2001; Rooney et al., 2007). Although pacing is probably the most common form of stereotypy observed in captive carnivores (Clubb and Mason, 2007) other stereotypical behaviors such as repetitive circling and gnawing on enclosure walls have also been observed (Beerda et al., 1999).

The prevalence of species-typical behaviors (behaviors apparent in the behavioral repertoire and budget of wild conspecifics) has also been used to evaluate enclosure condition (Kistler et al., 2009). Providing animals with the adequate space and materials needed for displays of species-typical behaviors has been shown to reduce abnormal behaviors and mitigate stress responses in several species (Vestergaard et al., 1997; Grindrod and Cleaver, 2001; Bolhuis et al., 2005). Previous research on gray wolves, red fox, and domestic dogs (Hubrecht et al., 1992; Nimon and Broom, 2001; Frézard and Le Pape, 2003) suggests that enclosure conditions influence the amount of time spent performing species-specific behaviors. It remains unclear, however, if the same holds true for coyotes. Shivik et al. (2009) found that enclosure type had a limited impact on the behavioral budget or repertoire of captive coyotes.

In addition to behavioral indices of stress, physiological indices are often used to investigate the impact of enclosure condition (Rooney et al., 2007). Heart rate, a measure of the sympathetic adrenal medullary (SAM) axis, is considered a sensitive and effective measure of the physiological response to stressful stimuli (Weisenberger et al., 1996; Boissy et al., 2007). Heart rate may also reflect psychogenic responses to other stimuli and events such as agonistic behavior between pen mates, isolation, and feeding when observed heart rates exceed those expected due to physical exertion alone (Kreeger et al., 1990; Palestrini et al., 2005).

Increased responsiveness to novel stimuli, both behaviorally and physiologically, has been linked to barren and spatially restricted enclosure conditions (Veissier et al., 1997). In pigs and mice, restrictive enclosures increase baseline heart rates and promote psychogenic responses to husbandry and experimental practices (Schouten et al., 1991; Marchant et al., 1997). Several studies have examined heart rate response to novel or aversive stimuli in canids and increased heart rates appear to be a common response in dogs, red fox and gray wolves (Kreeger et al., 1989; White et al., 1991; Palestrini et al., 2005). Heart rate increases have also been observed in response to, presumably, less aversive and more routine events such as caretaker approach and feeding in gray wolves (Kreeger et al., 1990). A comparison of heart rate responsiveness to stimuli among enclosure types has not been previously conducted in canids, although several studies have investigated the heart rate responses of dogs housed in animal shelters and research institutions.

The focus of this study was to examine the effect of enclosure type on captive coyotes (Canis latrans) by measuring differences in behavior and heart rate. Captive coyote behavioral budgets and repertoire were compared among enclosure types and to a wild reference population with an emphasis on the prevalence of abnormal and species-specific behaviors. Baseline heart rates and heart rate responses to food delivery and an intrusive human activity (fecal collection) were also compared among enclosure types.

\section{Materials and methods}

\subsection{Subjects and experimental design}

This study was conducted using 10 (six male and four female) parent-reared coyotes maintained in the colony at the United States Department of Agriculture (USDA), Animal Plant and Health Inspection Services (APHIS), Wildlife Services (WS), National Wildlife Research Center (NWRC) Predator Research Station in Millville, UT, USA. Coyotes were between five and eight years of age when this study was conducted from November 2003 through January 2004. The study was conducted during winter months to minimize forage related behavior differences between captive and wild coyotes; food availability for wild coyotes is most similar to that of captive coyotes during the winter due to increased carcass availability (Gese et al., 1996). Throughout the study each coyote was fed one daily ration of $650 \mathrm{~g}$ of commercial mink food diet (Fur Breeders Agricultural Cooperative, Logan, UT, USA) and water was provided ad libitum. Coyotes on this study received the same regimen of feeding and care as non-study animals.

In this study we used a three time period, three treatment cross-over study design where subjects were housed within a different treatment enclosure: kennel (K), small pen $(S)$, or large pen (L) each period. Each treatment sequence (KSL, KLS, SKL, SLK, LKS, LSK) was randomly assigned to one male and one female coyote, with the exception of KSL and KLS which were assigned to one male each. The start and end dates for each treatment period was as follows: period one 15 November 2003 to 3 December 2003; period two 4 December 2003 to 19 December 2003; and period three 20 December 2003 to 6 January 2004. No data were collected prior to day 8 of each period to allow time for the coyotes to acclimate to their new enclosures and provide a washout period between treatments (Gilbert-Norton et al., 2009). Enclosure histories varied between subjects; however, all coyotes had prior exposure to both kennels and large pens. No coyote had prior experience in the newly constructed small pens. Directly before study onset, each subject was maintained individu- 
ally. However, all subjects had previous experience living both singly and as part of a pair.

\subsection{Monitoring of heart rate}

To facilitate remote heart rate monitoring during the study all 10 coyotes were surgically implanted with a heart rate transmitter one month prior to study onset. Two additional female coyotes had also been implanted with heart rate transmitters, but transmitters were removed due to medical complications prior to study onset, and the two additional females were not included in this study. All animal care and study procedures were approved by the National Wildlife Research Center's Institutional Animal Use and Care Committee (QA\# 1083).

\subsubsection{Heart rate transmitters}

Heart rate transmitters (model HR-300L Telonics, Mesa, AZ, USA) weighed approximately $42 \mathrm{~g}$, and were cylindrical in shape measuring $9.5 \mathrm{~cm}$ in length and $2 \mathrm{~cm}$ in diameter. Transmitters were coated with a biologically inert wax coating that did not provide for the attachment of external sutures to secure the transmitter in place. Therefore, prior to transmitter implantation, two 20-gauge stainless steel stay sutures were wrapped and then tightened around the body of each transmitter (one at each pole) to allow the transmitter to be secured against the abdominal wall.

\subsubsection{Implantation surgery and post-operative care}

Each coyote was anesthetized with a mixture of $25 \mathrm{mg}$ xylazine (TranquiVed, Vedco, St. Joseph, MO, USA) and $150 \mathrm{mg}$ ketamine hydrochloride (Ketaset, Fort Dodge, Overland Park, KS, USA). Coyotes also received injections of $50 \mathrm{mg}$ of carprofen (Rymadil, Pfizer, Exton, PA, USA) and $2.5 \mathrm{mg}$ butorphanol tartrate (Torbugesic, Fort Dodge, Overland Park, KS, USA) as additional analgesics while under sedation. Heart rate transmitters were surgically implanted by following the surgical protocol described by Kreeger (1988), for a detailed description see Brummer (2007). Aseptic techniques were used throughout surgery. Briefly, after a 10-12 cm midline incision was made, the cold sterilized radio transmitter was placed in the peritoneal cavity with the two electrodes extending out of the cranial aspect of the incision. The positive electrode was positioned on the left side of the thorax and the negative electrode was positioned on the right side of the thorax. The transmitter was held in place against the abdominal wall by the stainless steel stay sutures. The electrodes were stretched along the ventral thorax and drawn up sub-dermally through stab incisions made $2 \mathrm{~cm}$ anterior to each electrode terminus. Skin incisions made for electrode and transmitter placement were closed using absorbable sutures.

Each implantation surgery was immediately followed with an electrocardiograph (BASi Vetronics System/3 ECG Analyzer, West Lafayette, IN, USA) to test transmitter accuracy. All transmitters appeared to be working correctly when checked with the ECG. Following ECG, each coyote received a $2 \mathrm{~mL}$ prophylactic injection of penicillin (Twin Pen, Agrilabs, St. Joseph, MO, USA).

Each coyote's implantation site and body temperature was monitored daily for the first week following surgery and then every other day for a second week. For the treatment of pain, coyotes received $25 \mathrm{mg}$ carprofen tablets along with their daily food ration for the first four days following surgery. In addition, coyotes received $125 \mathrm{mg}$ amoxicillin (Clavamox, Pfizer, Exton, PA, USA) twice daily for 14-21 days. To treat the chronic inflammation of implantation site, $10 \mathrm{mg}$ prednisone (Prednisone, West-Ward Pharmaceutical, Eatontown, NJ, USA) was administered once daily, with food, until transmitters were removed upon study completion. During the study, incision sites and body temperature were checked at the onset of each treatment period and once within each treatment period.

Within one month after the study ended, all heart rate transmitters were removed. Anesthesia, surgical preparations, and analgesics administered were identical to the implantation surgery. Following anesthesia, each coyote's transmitter was again checked for accuracy using an ECG. All transmitters appeared to be working correctly when checked with the ECG. Transmitter and electrode leads were then removed using aseptic techniques. Post-operative care was identical to that described for implantation surgery.

\subsection{Enclosure treatments}

\subsubsection{Large pens}

For the large pen treatment, coyotes were individually maintained in $1000 \mathrm{~m}^{2}$ tear-drop shaped outdoor pens. Adjacent pens shared a cement wall where the pens converged to a common observation building. However, neighbors could view one another through the chain-link fencing that enclosed the wide, round end of each pen. Large pen enclosures were located an average distance of $87.6 \mathrm{~m}$ from areas of human activity (shop and office buildings) and an average distance of $12.4 \mathrm{~m}$ from non-study coyotes. Pen floors consisted of natural substrate of soil, low vegetation and some grasses. One manufactured PVC den box $(0.5 \mathrm{~m}$ high $\times 0.5 \mathrm{~m}$ diameter $)$ was available for use. Each pen also contained two $0.7 \mathrm{~m}$ high plywood shade tables $(1.2 \mathrm{~m} \times 0.9 \mathrm{~m})$ that coyotes could use as a shelter or a platform. Large pen animals were normally attended to twice daily. During the first visit, animals were observed for injuries, and the watering system was checked. Coyotes were fed a daily ration during the second visit.

\subsubsection{Small pens}

Within the small pen enclosure, study subjects were individually maintained in one of four adjacent $65.5 \mathrm{~m}^{2}$ chain link enclosed outdoor pens with $1 \mathrm{~m}$ spacing between them. Small pen enclosures were located an average distance of $138.9 \mathrm{~m}$ from areas of human activity and an average distance of $19.9 \mathrm{~m}$ from non-study coyotes. Small pens provided approximately $6.0 \%$ of the floor area that large pens did. Pen floors consisted of bare dirt patches mixed with low vegetation. Each pen contained a plywood shade table and a manufactured den box. Small pen animals typically received two daily visits by the investigator or an alternate caretaker. These visits mirror those described for large pens. 


\subsubsection{Kennels}

In kennels, coyotes were individually housed in chainlink kennels that were $3.7 \mathrm{~m}$ long $\times 0.9 \mathrm{~m}$ wide $\left(3.3 \mathrm{~m}^{2}\right.$ floor space) in size. Kennels were approximately $5.0 \%$ of the size of small pens and $0.3 \%$ of the large pens. Kennels were not enclosed in a building but were situated on cement flooring, underneath a roof that sheltered the kennels from direct precipitation or sun but exposed to ambient temperatures. Kennels were adjacent to each other but spaced $1 \mathrm{~m}$ apart. Kennel enclosures were located an average distance of $55.2 \mathrm{~m}$ from areas of human activity and an average distance of $5.7 \mathrm{~m}$ from non-study coyotes. Each kennel contained a manufactured den box. For husbandry purposes, kennel animals normally received three daily visits by an animal care taker. Coyotes were first observed for injury and the watering system was checked, then individual kennels were entered by a technician and sprayed or scraped clean, and finally coyotes were fed their daily ration.

\subsubsection{Wild coyotes}

Behavior data from wild coyotes were collected through direct observation in the Lamar Valley, Wyoming, USA from November through January in 1991-1993 (Gese, 1995). A subset of Gese (1995) behavioral observations on six male and four female, non-breeding adults $(n=5)$ and yearlings $(n=5)$, totaling $197 \mathrm{~h}$ was used for comparison to the captive coyotes.

\subsection{Experimental stimuli}

\subsubsection{Food delivery}

Regardless of enclosure type, each coyote was normally fed once daily between 09:00 and 12:00 h by the technician opening the kennel door or pen gate and attaching a food bowl to the chain link on the inside of the kennel door or pen gate. For food delivery, kennels were typically approached on foot with a food cart in tow; small and large pens were approached by vehicle. The small pens were consistently fed just prior to large pens.

\subsubsection{Fecal collection}

Fecal collections consisted of the investigator entering the enclosure and walking throughout the area with a short handled hoe and collection tray to collect feces. Daily removal of feces was standard procedure for animals in kennel enclosures. However, pen enclosures were not typically cleaned. Fecal collections took approximately $1 \mathrm{~min}$ for a kennel, $4 \mathrm{~min}$ for a small pen and $6 \mathrm{~min}$ for a large pen. Fecal collections took place three times (days 9, 14 and 15) during treatment periods 1 and 2, and twice (days 9 and 16) in period 3. On collection days, fecal collections replaced routine kennel cleaning.

\subsection{Data collection}

\subsubsection{Captive coyote behavior}

Focal observations of each animal were recorded utilizing infra-red illuminating cameras (Tevicom Model PC-172EX and Supercircuits Model PC-125EX, Supercircuits, Liberty Hill, TX, USA) situated at the back of each kennel and in multiple locations around the perimeter of each pen. Behavior was recorded continuously on real time video recorders (Sanyo Model SRT-612DC, Chatsworth, CA, USA; Mitsubishi Model HS-1280U, Cypress, CA, USA) during days $15-17$ of treatment period 1 , days 14-16 of period 2, and days $16-18$ of period 3. Each subject's behavior was observed during six non-consecutive $1 \mathrm{~h}$ blocks recorded during those three day time periods. Due to weather related camera failure, coyote \#5546 M was only observed in two enclosure types. Observations were balanced throughout various levels of human activity by sampling from three different periods of the day, morning 06:45-10:00 h, early afternoon 10:01-13:15 h, and late afternoon $13: 16-16: 30 \mathrm{~h}$. A total of $174 \mathrm{~h}$ of observation were imported into Observer 5.0 software package (Noldus Information Technology, Wageningen, The Netherlands) and scored by a single investigator. Behaviors were categorized into discrete states (Table 1) and scored in terms of duration of occurrence.

Table 1

Captive coyote behavior categories.

\begin{tabular}{|c|c|}
\hline Behavior & Description \\
\hline Physical activity & $\begin{array}{l}\text { Any locomotive behavior that was not stereotypic, directed at another coyote, or exploratory in nature; includes } \\
\text { walking, trotting, running and jumping on and off of enclosure structures }\end{array}$ \\
\hline Stereotypy & $\begin{array}{l}\text { Any behavior that was repetitive and rigid in appearance; includes pacing, walking in small tight circles, and pivoting } \\
\text { back and forth. Behavior onset was marked following 3rd consecutive repetition of behavior }\end{array}$ \\
\hline Exploratory & $\begin{array}{l}\text { All behaviors related to investigating the environment; includes sniffing the ground, air or object; walking or standing } \\
\text { with nose close to ground; sniffing then licking objects and close visual inspection of objects }\end{array}$ \\
\hline Stand and scan & Standing in place and visually surveying environment \\
\hline Lay/sit & $\begin{array}{l}\text { Laying with head up or down, sitting; also includes all times when coyote is in den box and there is no human activity } \\
\text { in close proximity }\end{array}$ \\
\hline Howl & Vocalizing \\
\hline Territorial & $\begin{array}{l}\text { Agonistic behaviors directed at neighboring coyotes such as fence bounding or stalking. Also behaviors related to } \\
\text { scent marking; includes scratching ground, urinating, defecating, scratching over feces and urine, rolling on ground, or } \\
\text { rubbing sides of body on objects }\end{array}$ \\
\hline Hiding & $\begin{array}{l}\text { Hiding in den box when approached by animal care technician or when in close proximity of human activity (within } \\
30.5 \mathrm{~m} \text { ) }\end{array}$ \\
\hline Oral/eat & $\begin{array}{l}\text { Eating from food bowl or off of the ground. Also includes other oral behaviors directed at food bowl, water bowl, or } \\
\text { the automatic watering system }\end{array}$ \\
\hline Grooming & Grooming or other self-directed activity such as scratching \\
\hline Predatory & Any behavior that was directed at real or unseen prey item; includes chasing magpies, stalking and pouncing \\
\hline Dig & Digging in snow, dirt or corn cob bedding \\
\hline
\end{tabular}


Table 2

Wild coyote behavior categories (definitions derived from Gese et al., 1996).

\begin{tabular}{|c|c|}
\hline Behavior & Description \\
\hline Physical activity & $\begin{array}{l}\text { Locomotive behaviors such as walking, trotting, and running. Does not include locomotive behaviors listed within the } \\
\text { explore/predatory category }\end{array}$ \\
\hline Stereotypy & $\begin{array}{l}\text { Any behavior that was repetitive and rigid in appearance; includes pacing, walking in small tight circles, and pivoting } \\
\text { back and forth }\end{array}$ \\
\hline Exploratory/predatory & $\begin{array}{l}\text { Exploratory behaviors including searching ground, standing and sniffing ground; and predatory behaviors such as } \\
\text { orienting towards prey, stalking, pouncing and chasing. Events of prey capture were not included }\end{array}$ \\
\hline Stand and scan & Standing in place and visually surveying environment \\
\hline Lay/sit & Laying on sides with head up or down or sitting on haunches \\
\hline Oral/eat & Eating from ungulate carcass, carcass scraps or small prey item \\
\hline Dig & Digging in snow or dirt \\
\hline
\end{tabular}

\subsubsection{Wild coyote behavior}

Wild coyote behavioral categories were derived from the definitions of Gese et al. (1996) (Table 2). Behavior categories described for wild coyotes were more broadly defined than those of captive coyotes (Table 1). Other behaviors of wild coyotes such as socializing and prey capture events were not included for comparison due to the inability of captive coyotes to display these behaviors.

\subsubsection{Coyote heart rate}

Transmitted heart rate data were received using a Lotek Wireless SRX_400 receiver (Newmarket, Ontario, CA, USA) and downloaded to a computer using the associated WinHost software package (version 4.3 Lotek Wireless Inc., Newmarket, Ontario, CA, USA). Each receiver recorded the heart rate in beats per minute at $22 \mathrm{~s}$ intervals. Heart rate data were continuously recorded on days 8-10 and 15-17 of period 1 , days $8-10$ and $14-16$ of period 2 , and days $8-10$ and $16-18$ of period 3 .

\subsubsection{Human activity}

Human activity (e.g. animal feeding) was recorded throughout the study on data sheets set-up at sign-in/signout stations located at all entrance and exit points to kennel and pen areas.

\subsection{Statistical analysis}

Behavioral budgets for each enclosure type and the wild reference population were calculated using the mean of time spent performing a behavior for all individual coyotes within that setting. Baseline heart rates for each coyote, within each enclosure type, were calculated as the mean of all heart rates recorded between civil twilight hours, when the coyote was undisturbed by human presence in its immediate surroundings. Mean heart rate responses to the food delivery and fecal collections were calculated using individual means of all heart rates recorded from the time a technician entered the kennel or pen to the time the technician left. For latency to return to baseline calculations, baseline heart rate was defined as baseline heart rate +1 standard deviation (SD) (Beerda et al., 1998). Mean latency to return to baseline was calculated using individual mean latencies.

All statistical analysis was performed using SAS statistical software, Version 9.1 (SAS Institute, Cary, NC, USA). Captive coyote behavior data, baseline heart rate and heart rate responses to food delivery and fecal collection were compared among enclosure types using analysis of variance (ANOVA) for repeated measures. We examined treatment sequence, treatment period, and enclosure type as fixed effects. Additionally, we examined the effect of carryover between treatments for all heart rate data. No evidence of carryover between treatments was found. Behavior data could not be analyzed for carryover due to missing values. Significant enclosure effects were further investigated using a Tukey post hoc comparison of enclosure types. The baseline heart rate data required inverse transformation, and all latency data required square root transformation to normalize distributions prior to analysis with ANOVA. We confirmed model fit by examining the normality and homogeneity of residuals.

Behavioral budgets between wild and captive coyotes were compared by enclosure type using two sample $t$-tests. We used the Satterthwaite approximation to compute the degrees of freedom for all comparisons. Wild coyote behavior data were confirmed to have a normal distribution prior to analysis. Infrequently occurring behaviors could not be analyzed parametrically and have been reported descriptively.

\section{Results}

\subsection{Effect of enclosure type on behavior}

Behavioral budgets of captive coyotes varied by enclosure type. However, five behavioral categories (physical activity, stereotypy, exploratory, stand and scan, and lay/sit) made up the majority ( $88 \%$ ) of behaviors observed. Analysis revealed that the type of enclosure had a significant effect on the behavior of captive coyotes within the following categories: physical activity, stereotypy, lay/sit, stand and scan, and exploratory (Table 3). Compared to small and large pens, coyotes spent a significant amount of time performing stereotypic behaviors when housed in kennels. In contrast, coyotes spent less time stereotyping and significantly more time displaying exploratory and stand/scan behaviors when living in large pens. In small pens, the mean percentages of stereotypic, exploratory, and stand and scan behaviors were intermediate to those for kennels and large pens. Coyotes housed in small pens spent the most time resting.

Many observed behaviors were not prevalent enough to accommodate inferential analysis. Coyotes spent rela- 
Table 3

Percentage of observation time (least squares means \pm SEM) spent performing a behavior for all coyotes within each enclosure type.

\begin{tabular}{|c|c|c|c|c|c|}
\hline Behavior & Kennel $(n=10)$ & Small pen $(n=10)$ & Large pen $(n=9)$ & $F_{(2,15)}$ & $P$ \\
\hline Physical activity & $15.5 \pm 2.03^{a}$ & $9.06 \pm 2.0^{\mathrm{b}}$ & $17.8 \pm 2.13^{a}$ & 6.49 & 0.009 \\
\hline Stereotypy & $34.3 \pm 3.38^{a}$ & $8.4 \pm 3.34^{\mathrm{b}}$ & $7.0 \pm 3.56^{\mathrm{b}}$ & 20.04 & $<0.0001$ \\
\hline Exploratory & $3.0 \pm 0.76^{a}$ & $5.3 \pm 0.75^{\mathrm{a}, \mathrm{b}}$ & $8.6 \pm 0.8^{\mathrm{b}}$ & 13.04 & 0.0005 \\
\hline Stand/scan & $8.9 \pm 2.2^{\mathrm{a}}$ & $18.0 \pm 2.18^{\mathrm{b}}$ & $23.0 \pm 2.3^{\mathrm{b}}$ & 13.9 & 0.0004 \\
\hline Lay/sit & $29.5 \pm 5.56^{a}$ & $50.7 \pm 5.51^{\mathrm{b}}$ & $33.4 \pm 5.83^{a}$ & 5.46 & 0.01 \\
\hline
\end{tabular}

Values with different superscripts (a,b) within row are significantly different (Tukey post hoc comparison $P<0.05$ ).

tively small percentages of time howling (kennel: $\bar{x}=0.5$, $\mathrm{SD}=0.46, n=10$; small pen: $\bar{x}=1.5, \mathrm{SD}=0.96, n=10$; large pen: $\bar{x}=1.4, \mathrm{SD}=0.59, n=9$ ), grooming (kennel: $\bar{x}=3.6$, $\mathrm{SD}=3.46, n=10$; small pen: $\bar{x}=2.6, \mathrm{SD}=2.32, n=10$; large pen: $\bar{x}=1.3, \mathrm{SD}=0.59, n=9$ ), and hiding (kennel: $\bar{x}=0.8$, $\mathrm{SD}=0.59, n=10$; small pen: $\bar{x}=0.001, \mathrm{SD}=0.004, n=10$; large pen: $\bar{x}=0.0, S D=0.0, n=9)$. Data for territorial, digging, and predatory behaviors have not been included because these behaviors occurred rarely ( $<1 \%$ of observation time) and are not specifically used as indicators of enclosure quality. There was little difference in the behavioral repertoire among enclosure types with the exception of digging, which was only observed in the small pens, and hiding which was never observed in the large pens.

\subsection{Comparisons of behaviors of wild coyotes and captive coyotes}

The most common behaviors observed in wild coyotes (stand and scan, exploratory/predatory, lay/sit, and physical activity) were the same as those for the captive coyotes with the exception of stereotypy, which was only observed under captive conditions. However, results show that the differences in physical activity and exploratory/predatory behaviors were significant or nearly significant between wild and captive coyotes in all enclosure types (Table 4). Wild coyotes spent significantly more time standing and scanning than kennel coyotes, and significantly less time laying and sitting than small pen coyotes.

\subsection{Effect of enclosure type on baseline heart rates}

Baseline heart rates were generally highest in kennel enclosures, but did not differ significantly among enclosure types (Table 5).

\subsection{Effect of enclosure type on heart rate response to experimental stimuli}

Regardless of enclosure size, heart rates increased prior to coyotes being fed, peaked at or just before food delivery, and began to decrease immediately thereafter (Fig. 1A). During food delivery, mean heart rate (HR) was highest in small pens but did not differ significantly among enclosure types (Table 5). A post hoc descriptive analysis, of behavior during food delivery, indicated that animals in kennels displayed the highest average of hiding behavior (kennels: $\bar{x}=79.8, \mathrm{SD}=44.61 n=5$; small pens: $\bar{x}=0.0$, $\mathrm{SD}=0.0, n=6$; large pens: $\bar{x}=0.0, \mathrm{SD}=0.0, n=5$ ), and animals housed in small pens displayed the highest average for overall activity when stereotypy and physical activity were combined (kennels: $\bar{x}=3.7, \mathrm{SD}=8.19, n=5$; small pens: $\bar{x}=90.3, \mathrm{SD}=17.86, n=6$; large pens: $\bar{x}=83.7, \mathrm{SD}=18.23$, $n=5)$.

Heart rates increased prior to fecal collections in all enclosure types, and peaked at or just prior to a technician entering the enclosure. Heart rates began to decrease approximately 2 min after the technician left kennel enclosures and immediately after leaving small or large pen enclosures (Fig. 1B). Mean HR during fecal collection was lowest in large pen enclosures, and differed significantly between kennels and large pens (Table 5). Post hoc descriptive analysis of behavior during fecal collection showed that animals in kennels displayed the highest average of hiding behavior (kennels: $\bar{x}=96.8, \mathrm{SD}=6.56 n=7$; small pens: $\bar{x}=0.0, \mathrm{SD}=0.0, n=3$; large pens: $\bar{x}=0.0, \mathrm{SD}=0.0$, $n=7)$, and animals housed in large pens had the highest average for overall activity level (kennels: $\bar{x}=0.8$, $\mathrm{SD}=1.42, n=7$; small pens: $\bar{x}=59.6, \mathrm{SD}=35.15, n=3$; large pens: $\bar{x}=71.7, \mathrm{SD}=24.17, n=7)$. Latency to return to baseline differed significantly among enclosures (Table 5). Kennels had the longest latency period, and large pens had the shortest.
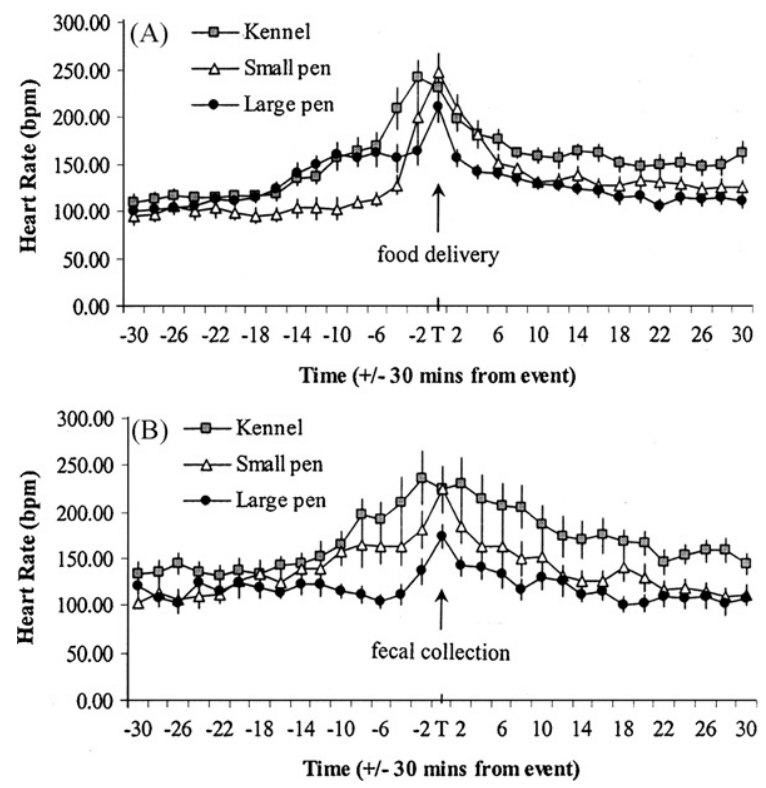

Fig. 1. Mean heart rates ( \pm SEM) for all coyotes within each housing type from 30 min prior to 30 min following the event of $(A)$ food delivery and (B) fecal collection at time $T$ (kennel: $n=10$; small pen: $n=10$; large pen: $n=10)$. 


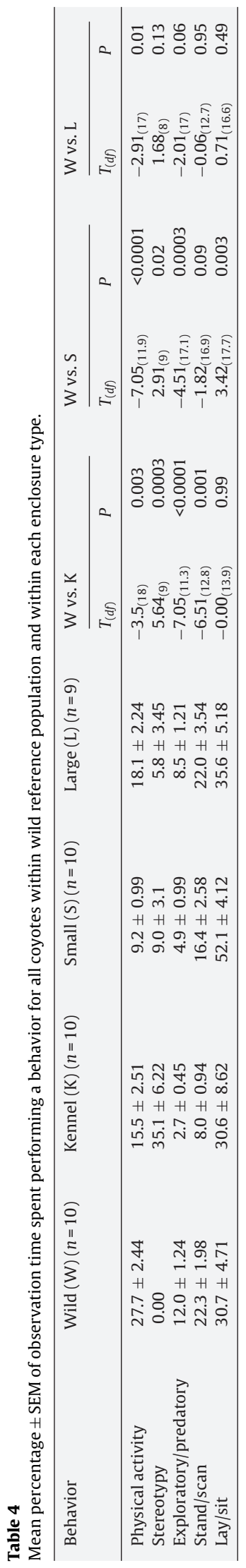

\section{Discussion}

The results of this study show that enclosure type influences the behavioral budgets of captive coyotes. The average time spent performing behaviors such as physical activity, lay/sit, exploratory, and stand and scan differed significantly among enclosure types. However, the most notable of behavioral changes was the amount of time spent stereotyping. All study coyotes paced within each enclosure type; however, coyotes living in kennels spent significantly more time pacing or performing stereotypic circling and pivoting than in either small or large pens. This finding was expected, as pacing in carnivores typically increases as cage size decreases (Carlstead, 1996) and other canids have been observed to pace more frequently when housed in small pens (Hubrecht et al., 1992; Kreeger et al., 1996). Additionally, kennels lack the environmental variability of large and small pens. Reduced environmental complexity is often associated with small enclosures and has been found to induce stereotypy performance in a variety of species (Von Borell and Hurnik, 1991; Mallapur and Chellam, 2002; Garner et al., 2003). The increased husbandry intensity inherent to kennel housing may have also contributed to the increased stereotypy observed. Coyotes and other captive canids have been shown to react negatively to human activity (Sayles, 1984; Kreeger et al., 1996; Nimon and Broom, 2001).

Other factors that may influence stereotypic behavior include housing density and feeding schedules. Research on domestic dogs indicates that stereotypy is reduced when dogs are housed in groups, even when cage size is relatively small (Hubrecht et al., 1992; Beerda et al., 1999). Pacing in captive carnivores can also represent a form of food anticipatory activity related to predictable feeding times (Bassett and Buchanan-Smith, 2007). In this study, husbandry within all enclosure types was fairly consistent in time of occurrence and sequence of events, and all coyotes were housed individually. Thus, housing density and predictable husbandry may have contributed to the performance of stereotypic behaviors, but these factors do not account for the differences observed among enclosure types.

Other behavior changes common to spatially and socially restricted environments include increases in fearfulness, grooming and vocalizing (Hetts et al., 1992; Ruis et al., 2001; Beerda et al., 1999). Fearfulness is best approximated, in this study, by the amount of time the coyotes spent hiding in their den boxes. Hiding was observed in kennels and small pens, and grooming and howling were observed in all enclosure types. However, none of these behaviors occurred frequently enough to accommodate analysis and can only be described in a general sense. On average, coyotes spent more time hiding during human activity when housed in kennels than in either pen type. However, the close proximity of humans during routine husbandry may account for the increase. Grooming was observed most often in kennels and least often in large pens. Howling occurred most often in the small pens. Howling is suggested to be a means for coyotes to communicate one's location (Lehner, 2001) and it remains unclear if it can be used as an indicator of enclosure quality for coyotes. 
Table 5

Least squares means of baseline heart rate (no human activity) and heart rate responses to food delivery and fecal collection for all coyotes within each enclosure type. Standard error means $( \pm$ SEM) presented for untransformed data.

\begin{tabular}{|c|c|c|c|c|c|c|}
\hline & Response variable & Kennel $(n=10)$ & Small pen $(n=10)$ & Large pen $(n=10)$ & $F_{(2,14)}$ & $P$ \\
\hline Baseline & Mean HR (bpm) (INV)a & $0.008 \pm 0.0003(113.8)$ & $0.009 \pm 0.0003(102.5)$ & $0.009 \pm 0.0003(105.4)$ & 1.9 & 0.18 \\
\hline \multirow[t]{2}{*}{ Food delivery } & Mean HR (bpm) & $250.8 \pm 20.63$ & $258.6 \pm 19.8$ & $209.2 \pm 19.8$ & 2.33 & 0.13 \\
\hline & $\begin{array}{l}\text { Mean latency (s) to return to } \\
\text { baseline }+1 \mathrm{SD}(\mathrm{SQRT})^{\mathrm{a}}\end{array}$ & $25.0 \pm 2.52(626.0)$ & $25.1 \pm 2.39(629.0)$ & $20.1 \pm 2.39(403.6)$ & 1.39 & 0.28 \\
\hline Fecal & Mean HR (bpm) & $239.9 \pm 24.45^{x}$ & $214.0 \pm 23.75^{x, y}$ & $168.9 \pm 23.75^{y}$ & 3.95 & 0.04 \\
\hline collection & $\begin{array}{l}\text { Mean latency (s) to return to } \\
\text { baseline }+1 \mathrm{SD}(\mathrm{SQRT})^{\mathrm{a}}\end{array}$ & $33.8 \pm 4.57^{x}(1147.2)$ & $24.9 \pm 4.5^{y}(620.0)$ & $17.3 \pm 4.5^{y}(298.3)$ & 11.11 & 0.001 \\
\hline
\end{tabular}

Values with different superscripts ( $\mathrm{x}, \mathrm{y})$ within a row are significantly different (Tukey post hoc comparison $P<0.05$ ).

a Where data have been transformed the type of transformation, inverse (INV) or square root (SQRT), has been indicated. Least squares means have been back transformed and presented in parenthesis for ease of reading.

The comparison between captive and wild coyote behavioral budgets revealed that enclosure type does impact the proportion of species-typical behaviors performed, especially in the categories of physical activity, stereotypy, exploratory/predatory, and stand and scan. It has been suggested that pacing may be a form of locomotion that has simply been modified by spatial limitations (Hetts et al., 1992; Kreeger et al., 1996). In this study, wild coyotes spent significantly more time engaged in physical activity than captive coyotes in any enclosure type. However, when the categories of physical activity and stereotypy are combined, the overall physical activity of wild coyotes is markedly less than that of coyotes housed in kennels (Fig. 2). One possible reason for the difference is that wild coyotes were observed in multiple snow depths and locomotion in wild coyotes may be hindered by snow depth (Gese et al., 1996). Alternatively, the increase in overall activity for kennel animals may be related to the small enclosure size or the increased intensity of husbandry, both of which have been shown to increase activity levels in other species (Carlstead et al., 1993; Friend and Parker, 1999; Hansen and Berthelsen, 2000).

The performance of some species-specific behaviors increasingly approached that of wild coyotes as the captive enclosures gained in size and complexity. Captive coyotes spent the most time doing exploratory, and stand and scan behaviors when housed in large pens. Similar increases of exploratory behavior in response to increased enclosure size have also been observed in blue fox (Korhonen et al., 2001), domestic dogs (Spangenberg et al., 2006), and

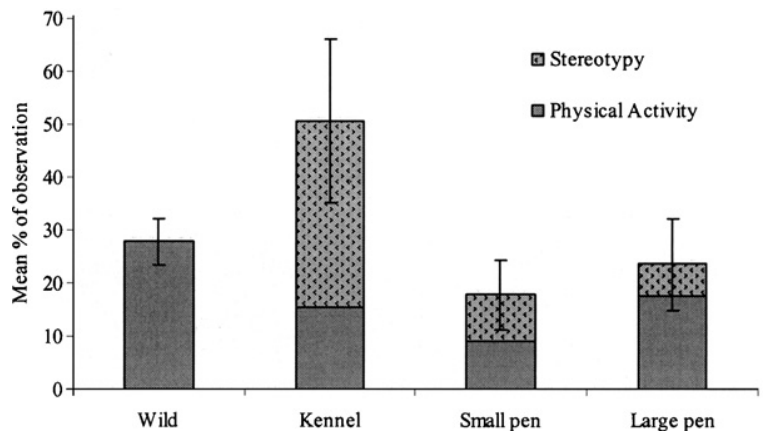

Fig. 2. Mean percentage ( $\pm \mathrm{CI} 90 \%)$ of time spent in overall activity (stereotypic and non-stereotypic physical activities combined) (wild: $n=10$; kennel: $n=10$; small pen: $n=10$; large pen: $n=9$ ).
Indian leopards (Mallapur and Chellam, 2002). The proportion of stand and scan behavior observed for captive coyotes in large pens was nearly equal to that of wild coyotes.

No stereotypic behavior was observed in wild coyotes, but stereotypies are rarely observed in the wild for any species (Garner et al., 2003). Stereotypy performance has been linked to the inability to perform species-typical behaviors in seals (Grindrod and Cleaver, 2001), polar bears (Wechsler, 1991), horses (McAfee et al., 2002) and laying hens (Vestergaard et al., 1997). However, the speciestypical behaviors of coyotes, as determined from the wild reference population, were largely represented in the behavioral budgets of captive coyotes, albeit in different proportions. This is concurrent with the finding of Shivik et al. (2009) that the behavioral repertoire of coyotes is largely unaffected when behaviors are measured using few, broad categories.

The baseline heart rates of captive coyotes varied considerably, but not significantly, among enclosure types. The average baseline heart rate was highest in kennels. Elevated baseline heart rates have been linked to small and environmentally sterile enclosures (Marchant et al., 1997) and may reflect a decreased ability to cope with stress (Meijer et al., 2006). However, the variation observed here readily reflects differences in behavioral budgets. In this study, overall activity levels were highest in kennels (Fig. 2). Alternatively, differences among enclosure types such as ambient temperature, location relative to human activity and the proximity of neighboring conspecifics may have also influenced baseline heart rates.

Regardless of enclosure type, coyotes responded to the experimental stimuli with increased heart rates. Heart rates can increase in response to both excitement and fear (Weisenberger et al., 1996), and the food delivery generally elicited higher heart rates than did the more intrusive human activity of fecal collection. Although heart rate responses to food delivery did not differ significantly among enclosure types, mean heart rate was highest in small pens. This was inconsistent with previous research on pigs, which suggested that heart rate responses to feeding increased as spatial restrictions increased (Schouten et al., 1991; Marchant et al., 1997). The elevated heart rate responses of coyotes in small pens may reflect the increased level of overall activity exhibited during food delivery, as revealed in a post hoc analysis, or psychogenic increases. 
In contrast, the elevated heart rates of coyotes housed in kennels were not attributable to overall activity levels. Coyotes in kennel enclosures often hid in their den boxes during food delivery. Thus, it is likely that these heart rate responses were indicative of psychogenic increases. Kreeger et al. (1990) observed a similar psychogenic response to feeding in gray wolves. It should be noted that the psychogenic increases observed here do not necessarily indicate that the coyotes perceived food delivery as stressful.

Enclosure type significantly influenced heart rate responses during fecal collections. Mean heart rates were lowest in large pens and similarly high for coyotes housed in kennels and small pens. This was expected as fecal collections were, presumably, aversive events and large pens offered the greatest amount of flight distance. A post hoc examination of behavioral responses revealed that coyotes in kennels hid in the den box during fecal collections, whereas coyotes in large pens were more physically active overall. Here too, the increases observed in kennel heart rates were not accounted for by physical activity, and are therefore suggestive of psychogenic increases. Psychogenic increases have been observed in response to aversive events such as agonistic encounters, capture, and transport (Kreeger et al., 1996; Lefcourt et al., 1999; Waas et al., 1999). For example, Palestrini et al. (2005) found that heart rates in dogs remained elevated despite minor motor movement, under stressful conditions. Given the circumstances, the psychogenic increases observed in response to fecal collection appeared to reflect stress.

Latency to return to baseline heart rates following fecal collection was significantly longer in kennels than in either pen type. Fecal collection took the least amount of time in the kennels and the greatest amount of time in the large pens. These results indicate that heart rate responses to intrusive human activities are significantly impacted by differences in enclosure type and that coyotes housed in large pens show the least overall response (Fig. 1B).

\section{Conclusion}

In conclusion, the behavioral budgets of captive coyotes varied by enclosure type and kennels had the greatest effect on the performance of stereotypic behaviors.

Of the enclosures tested, the behavioral budgets of coyotes housed in large pens were most similar to that of wild coyotes overall. The behavioral repertoire of wild coyotes was largely represented in that of captive coyotes regardless of enclosure type.

Enclosure type did not significantly influence baseline heart rates or heart rate responses to food delivery. However, heart rate responses to fecal collection were significantly higher in kennels than in large pens. Psychogenic increases were apparent in the heart rate responses of kennel-housed animals to both types of human activities.

The results of this study suggest that relative to living in outdoor pens, coyotes housed in kennels experience increased stress levels. Large outdoor pens appear to provide the best environment for captive coyotes in terms of behavioral similarity to wild conspecifics, and reduced stress responses.

\section{Acknowledgements}

This study was funded by the National Wildlife Research Center. We would like to thank the staff at the Wildlife Services National Wildlife Research Center's Predator Research Facility in Millville, UT, USA for their time, effort and help in this study. This study could not have been conducted without the help and support of Patrick Darrow, Jared Hedelius and Jeff Schultz. Thanks to Doris Zemlicka for her logistical support, and to Paige Groninger and Susan Durham for their statistical assistance.

\section{References}

Bassett, L., Buchanan-Smith, H.M., 2007. Effects of predictability on the welfare of captive animals. Appl. Anim. Behav. Sci. 102, 223-245.

Beerda, B., Schilder, M.B.H., Van Hooff, J.A.R.A.M., De Vries, H.W., Mol, J.A., 1998. Behavioural, saliva cortisol and heart rate responses to different types of stimuli in dogs. Appl. Anim. Behav. Sci. 58, 2365-2381.

Beerda, B., Schilder, M.B.H., Van Hooff, J.A.R.A.M., De Vries, H.W., Mol, J.A., 1999. Chronic stress in dogs subjected to social and spatial restriction: I. Behavioral responses. Physiol. Behav. 66, 233-242.

Boissy, A., Manteuffel, G., Jensen, M.B., Moe, R.O., Spruijt, B., Keeling, L.J., Winckler, C., Forkman, B., Dimitrov, I., Langbein, J., Bakken, M., Veissier, I., Aubert, A., 2007. Assessment of positive emotions in animals to improve their welfare. Physiol. Behav. 92, 375-397.

Bolhuis, J.E., Schouten, W.G.P., Schrama, J.W., Wiegant, V.M., 2005. Behavioural development of pigs with different coping characteristics in barren and substrate-enriched housing conditions. Appl. Anim. Behav. Sci. 93, 213-228.

Brown, K.J., Grunberg, N.E., 1996. Effects of environmental conditions on food consumption in female and male rats. Physiol. Behav. 60, 293-297.

Brummer, 2007. Effect of housing type on captive coyote (Canis latrans) behavior and physiology. Thesis. Utah State University, Logan.

Carlstead, 1996. Effects of captivity on the behavior of wild mammals. In: Kleimand, D.G., Allen, M.E., Thompson, K.V., Lumpkin, S. (Eds.), Wild Mammals in Captivity Principles and Techniques. University of Chicago Press, Chicago, pp. 317-333.

Carlstead, K., Brown, J.L., Strawn, W., 1993. Behavioral and physiological correlates of stress in laboratory cats. Appl. Anim. Behav. Sci. 38, 143-158.

Clubb, R., Mason, G.J., 2007. Natural behavioural biology as a risk factor in carnivore welfare: how analysing species differences could help zoos improve enclosures. Appl. Anim. Behav. Sci. 102, 303-328.

Fraser, A.F., Broom, D.M., 1997. Farm Animal Behaviour and Welfare. CAB International, Wallingford.

Frézard, A., Le Pape, G., 2003. Contribution to the welfare of captive wolves (Canis lupus lupus), a behavioral comparison of six wolf packs. Zoo Biol. 22, 33-44.

Friend, T.H., Parker, M.L., 1999. The effect of penning versus picketing on stereotypic behavior of circus elephants. Appl. Anim. Behav. Sci. 64, 213-225.

Garner, J.P., Mason, G.J., Smith, R., 2003. Stereotypic route tracing in experimentally caged songbirds correlates with general behavioural disinhibition. Anim. Behav. 66, 711-727.

Gese, 1995. Foraging ecology of coyotes in Yellowstone National Park. Dissertation. University of Wisconsin, Madison.

Gese, E.M., Ruff, R.L., Crabtree, R.L., 1996. Foraging ecology of coyotes (Canis latrans), the influence of extrinsic factors and a dominance hierarchy. Can. J. Zool. 74, 769-783.

Gilbert-Norton, L.B., Leaver, L.A., Shivik, J.A., 2009. The effect of randomly altering the time and location of feeding on the behaviour of captive coyotes (Canis latrans). Appl. Anim. Behav. Sci. 120, 179-185.

Grindrod, J.A.E., Cleaver, J.A., 2001. Environmental enrichment reduces the performance of stereotypic circling behaviour in captive common seal (Phoca vitulina). Anim. Welf. 10, 53-63.

Hansen, L.T., Berthelsen, H., 2000. The effect of environmental enrichment on the behavior of caged rabbits (Oryctolagus cuniculus). Appl. Anim. Behav. Sci. 68, 163-178.

Hetts, S.J., Clark, D., Calpin, J.P., Arnold, C.E., Mateo, J.M., 1992. Influence of housing condition on beagle behaviour. Appl. Anim. Behav. Sci. 34, 137-155.

Hubrecht, 2002. Comfortable quarters for dogs in research institutions. Available from: http://www.awionline.org/pubs/cq02/Cq-dogs.html. 
Hubrecht, R.C., Serpell, J.A., Poole, T.B., 1992. Correlates of pen size and housing conditions on the behaviour of kennelled dogs. Appl. Anim. Behav. Sci. 34, 365-383.

Jarvis, S., Calvert, S.K., Stevenson, J., VanLeeuen, N., Lawrence, A.B., 2002. Pituitary-adrenal activation in pre-parturient pigs (Sus scrofa) is associated with behavioral restriction due to lack of space rather than nesting substrate. Anim. Welf. 11, 371-384.

Kistler, C., Hegglin, D., Würbel, H., König, B., 2009. Feeding enrichment in an opportunistic carnivore: the red fox. Appl. Anim. Behav. Sci. 116, 260-265.

Korhonen, H., Jauhiainen, L., Niemela, P., Harri, M., Sauna-aho, R., 2001 Physiological and behavioural responses in blue foxes (Alopex lagopus), comparisons between space quantity and floor material. Anim. Sci. 72, 375-387.

Kreeger, 1988. The physiological, biochemical, and pathological responses of wild canids to stress. Dissertation. University of Minnesota, Minneapolis.

Kreeger, T.J., Kuechle, V.B., Mech, L.D., Tester, J.R., Seal, U.S., 1990. Physiological monitoring of gray wolves (Canis lupus) by radiotelemetry. J. Mammal. 71, 258-261.

Kreeger, T.J., Monson, D., Kuechle, V.B., Seal, U.S., Tester, J.R., 1989. Monitoring heart rate and body temperature in red foxes (Vulpes vulpes). Can. J. Zool. 67, 2455-2458.

Kreeger, T.J., Pereira, D.L., Callahan, M., Beckel, M., 1996. Activity patterns of gray wolves housed in small vs. large enclosures. Zoo Biol. $15,395-401$

Lefcourt, A.M., Erez, B., Varner, M.A., Barfield, R., Tasch, U., 1999. A noninvasive radiotelemetry system to monitor heart rate for assessing stress responses of bovines. J. Dairy Sci. 82, 1179-1187.

Lehner, 2001. Coyote communication. In: Bekoff, M. (Ed.), Coyotes Biology, Behavior and Management. Blackburn Press, Caldwell, pp. 127-162.

Mallapur, A., Chellam, R., 2002. Environmental influences on stereotypy and the activity budget of Indian Leopards (Panthera pardus) in four zoos in Southern India. Zoo Biol. 21, 585-595.

Marchant, J.N., Rudd, A.R., Broom, D.M., 1997. The effects of housing on heart rate of gestating sows during specific behaviors. Appl. Anim Behav. Sci. 55, 67-78.

McAfee, L.M., Mills, D.S., Cooper, J.J., 2002. The use of mirrors for the control of stereotypic weaving behaviour in the stabled horse. Appl. Anim. Behav. Sci. 78, 159-173.

Meehan, C.L., Mench, J.A., 2007. The challenge of challenge, can problem solving opportunities enhance animal welfare? Appl. Anim. Behav. Sci. $102,246-261$.

Meijer, M.K., Kramer, K., Remie, R., Spruijt, B.M., van Zutphen, L.F.M. Baumans, V., 2006. The effect of routine experimental procedures on physiological parameters in mice kept under different husbandry conditions. Anim. Welf. 15, 31-38.
Morgan, K.N., Tromborg, C.T., 2007. Sources of stress in captivity. Appl Anim. Behav. Sci. 102, 262-302.

Nimon, A.J., Broom, D.M., 2001. The welfare of farmed foxes Vulpes vulpes and Aloplex lagopus in relation to housing and management, a review. Anim. Welf. 10, 223-248.

Palestrini, C., Previde, E.P., Spiezio, C., Verga, M., 2005. Heart rate and behavioural responses of dogs in the Ainsworth's strange situation, a pilot study. Appl. Anim. Behav. Sci. 94, 75-88.

Rooney, N.J., Gaines, S.A., Bradshaw, J.W.S., 2007. Behavioural and glucocorticoid responses of dogs (Canis familiaris) to kennelling, investigating mitigation of stress by prior habituation. Physiol. Behav. 92 $847-854$

Ruis, M.A.W., te Brake, J.H.A., Engel, B., Buist, W.G., Blokhuis, H.J., Koolhaas, J.M., 2001. Adaptation to social isolation acute and long-term stress responses of growing gilts with different coping characteristics. Physiol. Behav. 73, 541-551.

Sayles, 1984. The effect of nutrition on maternal behavior among captive coyotes. Thesis. Utah State University, Logan.

Schouten, W., Rushen, J., DePassillé, A.M.B., 1991. Stereotypic behavior and heart rate in pigs. Physiol. Behav. 50, 617-624.

Shivik, J.A., Palmer, G.L., Gese, E.M., Osthaus, B., 2009. Captive coyotes compared to their wild counterparts, does environmental enrichment help? J. Appl. Anim. Welf. Sci. 72, 223-235.

Spangenberg, E.M.F., Bjorkland, L., Dahlborn, K., 2006. Outdoor housing of laboratory dogs, effects on activity, behavior and physiology. Appl. Anim. Behav. Sci. 98, 260-276.

Veissier, I., Chazal, P., Pradel, P., Le Neindre, P., 1997. Providing social contacts and objects for nibbling moderates reactivity and oral behaviors in veal calves. J. Anim. Sci. 75, 356-365.

Vestergaard, K.S., Skadhauge, E., Lawson, L.G., 1997. The stress of not being able to perform dustbathing in laying hens. Physiol. Behav. 62, 413-419.

Von Borell, E., Hurnik, J.F., 1991. Stereotypic behavior, adrenocortical function, and open field behavior of individually confined gestating sows. Physiol. Behav. 49, 709-713.

Waas, J.R., Ingram, J.R., Matthews, L.R., 1999. Real-time physiological responses of red deer to translocations. J. Wildl. Manage. 63, 1152-1162.

Wechsler, 1991. Stereotypies in polar bears. Zoo Biol. 10, 177-188.

Weisenberger, M.E., Krausman, P.R., Wallace, M.C., De Young, D.W., Maughan, O.E., 1996. Effects of simulated jet aircraft noise on heart rate and behavior of desert ungulates. J. Wildl. Manage. 60, 52-61.

White, P.J., Kreeger, T.J., Seal, U.S., Tester, J.R., 1991. Pathological responses of red foxes to capture in box traps. J. Wildl. Manage. 55, $75-80$. 